\title{
CONHECIMENTOS, ATITUDES E PRÁTICAS SOBRE CAPIVARAS EM ÁREAS ANTROPIZADAS INDENES PARA FEBRE MACULOSA: PERCEPÇÃO DA SOCIEDADE
}

\section{KNOWLEDGE, ATTITUDES AND PRACTICES ABOUT CAPYBARA IN ANTHROPIC AREAS: PERCEPTION OF SOCIETY}

\author{
Adalberto de Albuquerque Pajuaba Neto \\ Faculdade de Medicina Veterinária, Universidade Federal de Uberlândia \\ Centro de Controle de Zoonoses de Uberlândia, Prefeitura Municipal de Uberlândia \\ pajuabaneto@yahoo.com.br \\ Jean Ezequiel Limongi \\ Instituto de Geografia, Curso de Graduação em Saúde Coletiva, Universidade Federal de Uberlândia \\ jeanlimongi@gmail.com \\ Vivianne Peixoto da Silva \\ Instituto de Geografia, Curso de Graduação em Saúde Coletiva, Universidade Federal de Uberlândia \\ viviannepeixotos@gmail.com \\ Matias Pablo Juan Szabó \\ Faculdade de Medicina Veterinária, Universidade Federal de Uberlândia \\ szabo@ufu.br
}

\begin{abstract}
RESUMO
Objetivo: o presente estudo avaliou a percepção da sociedade sobre as capivaras e problemas associados a elas em área indene para febre maculosa brasileira. Método: Como instrumentos metodológicos para a coleta de dados foram utilizados o grupo focal e a entrevista individual semiestruturada. Resultados: Em um extremo estão aqueles mais desinteressados pela experiência reduzida e do outro lado aqueles com envolvimento maior dado pelo contato e experiências vividas. Notou-se que apesar de variações entre indivíduos e grupos, as percepções expostas neste trabalho são a resultante da mescla de informações provenientes da televisão, de terceiros e de outros meios de comunicação. As informações, ainda que mais precisas e técnicas no caso do poder público e grupos de técnicos em desenvolvimento na universidade, foram preponderantemente vagas e/ou fragmentadas, em alguns casos conflitantes. Conclusão: Os problemas com capivaras são multifacetados, fundamentalmente ecológicos, complexos e não admitem soluções rápidas. Amenizar essa realidade é subtrair da sociedade elementos para tomada de decisões racionais efetivas assim como a noção dos ônus e bônus que acompanham cada escolha. A ausência dessa percepção mais real nos munícipes certamente suscita descontentamento e desobediência civil independentemente de decisões tomadas.
\end{abstract}

Palavras-chave: Áreas antropizadas. Animais silvestres. Conhecimentos, Atitudes e Práticas em Saúde. Capivara.

\begin{abstract}
Objective: The present study evaluated the perception of society on capybaras and related problems in a non-endemic area for Brazilian spotted-fever. Method: As methodologica instruments for data collection, the focus group and the semi-structured individual interview were used. Results: At one extreme are those most disinterested due to reduced or lack of experience, and, on the other hand, those with greater involvement given by the contact and experiences. It was noticed that, despite differences among individuals and groups, prevailing perceptions exposed in this work are the result of a mixture of information from television, other media and third parties. Knowledge, although more precise and technical in the case of the public power and groups of technicians under training in University, was
\end{abstract}

Recebido em: 01/10/2019

Aceito para publicação em: 07/11/2019 
predominantly vague and/or fragmented, in some cases conflicting. Conclusion: The problems with capybaras are multifaceted, fundamentally ecological and complex and do not admit quick solutions. To ameliorate this reality is to subtract from society key elements for rational and effective decision making as well as the notion of the liens and bonuses of each choice. The absence of this real perception in the citizens certainly arouses dissatisfaction and civil disobedience regardless of decisions taken.

Keywords: Anthropic areas. Animals, Wild. Health, Knowledge, Attitudes, Practice. Capybara.

\section{INTRODUÇÃO}

Capivara (Hydrochoerus hydrochaeris), família Hydrochoeridae, é o maior roedor existente e possui ampla distribuição geográfica, compreendendo toda a América do Sul, com exceção do Chile. Este roedor está presente nos 26 Estados brasileiros e o Distrito Federal, sempre associado a áreas ribeirinhas, lacustres ou alagadas (MOREIRA et al, 2013).

A partir de um passado recente notou-se a ocupação de áreas antropizadas por capivaras, notoriamente daquelas urbanas (QUEIROGAS et al, 2012; ALMEIDA et al, 2013). Nestas a densidade dos animais tende a ser maior do que em áreas naturais preservadas (ALMEIDA; BIONDI; MONTEIRO FILHO, 2013). A ausência de predadores naturais (onças, serpentes e jacarés) aliado aos hábitos alimentares não seletistas e elevada capacidade reprodutiva contribuem para o estabelecimento dessa espécie em áreas antrópicas e justifica a densidade aumentada. Porém, a abundância de capivaras em áreas ocupadas por seres humanos, bem como o risco de transmissão de doenças gera conflitos na sociedade e a partir disso uma nova categorização para essa espécie foi estabelecida, a de população-problema (MOREIRA; PIOVESAN, 2005). Esses problemas incluem, entre outros, causar acidentes automobilísticos, ocorrência do afogamento de capivaras em piscinas, invasão e destruição de jardins, ataques a cães e mais raramente a pessoas (MOREIRA: PIOVEZAN, 2005). Destaca-se como principal problema gerar infestação ambiental por carrapatos agressivos ao ser humano e, em alguns locais, a transmissão para seres humanos do agente da Febre Maculosa Brasileira (FMB), a bactéria Rickettsia rickettsii por estes carrapatos (QUEIROGAS et al, 2012; LABRUNA, 2009; SZABÓ; PINTER; LABRUNA, 2013). A FMB é uma infecção bacteriana, de notificação compulsória e de elevada letalidade e é reconhecida como um problema emergente de saúde pública (ANGERAMI et al, 2009).

Por outro lado, é bem estabelecido que áreas verdes e animais, a natureza enfim, exercem um efeito benéfico para o bem-estar humano (BRATMAN; HAMILTON; DAILY, 2012; NAGASAWA et al, 2015). Sendo assim a percepção humana sobre a presença das capivaras em áreas antropizadas pode ser conflitante; induzir repúdio se relacionado a doenças, parasitismo por carrapatos ou destruição de plantações ou, de forma oposta, induzir o bem-estar com visão de um animal selvagem carismático em áreas verdes na proximidade de pessoas. De fato, a capivara foi recentemente listada entre os três principais animais selvagens em conflito com humanos (MARCHINI; CRAWSHAW, 2015). As decisões do poder público sobre a forma de lidar com as capivaras são invariavelmente controversas e até incitam a desobediência civil. Porém, apesar da divulgação frequente pela mídia de conflitos sobre capivaras em diversos locais no Brasil, envolvendo sociedade civil, agentes da área ambiental e de saúde pública, administrações públicas e justiça, notadamente em São Paulo e Minas Gerais, a percepção e os sentimentos da população sobre estes animais ainda precisam ser melhor avaliados. Pelos expostos percebe-se que, para uma atuação técnica efetiva para a solução dos problemas envolvendo capivaras, qualquer que seja esta, a colaboração da população é fundamental. Em sendo assim, a avaliação da percepção da sociedade sobre capivaras em áreas urbanas é primordial para o estabelecimento de um canal de comunicação com o poder público. Esta comunicação é fundamental para explicação e posterior execução de ações técnicas apropriadas com a participação ou pelo menos a anuência da população.

Uberlândia é a segunda cidade mais populosa de Minas Gerais e sua zona urbana possui diversas populações de capivaras (QUEIROGAS et al, 2012). As áreas verdes urbanas do município e utilizadas pelas capivaras, são infestadas por carrapatos expondo os usuários às picadas 
(QUEIROGAS et al, 2012). Porém, a saber, o município não é tem registro de caso de febre maculosa brasileira. Este estudo teve como objetivo avaliar a percepção da sociedade civil, de organizações governamentais e não governamentais e o poder público sobre a capivara e os problemas associados a elas, em áreas urbanas do município de Uberlândia, Minas Gerais, além de detectar as fontes de informação usadas pela sociedade para desenvolver juízo sobre as capivaras em áreas urbanas.

\section{METODOLOGIA}

Trata-se de um estudo qualiquantativo que foi realizado no município de Uberlândia, Minas Gerais, no período de 2015 a 2016. Uberlândia está localizada na bacia do Rio Paranaíba, ocorrendo em seu território várias sub-bacias de pequenos e médios córregos com papéis importantes em sua conformação.

O município tem onze áreas protegidas pela legislação ambiental, com a presença de mata ciliar às margens dos cursos d'água que os protegem contra assoreamento e suas encostas contra erosão, contribuindo para a preservação da fauna e da flora do cerrado (UFU, 2016).

Uberlândia é o segundo município mais populoso do estado, e como outras cidades no país possuem características ecológicas que favorecem a manutenção de diversos grupos de capivaras urbanas em toda extensão do Rio Uberabinha e nos córregos que cortam a cidade. Infestações intensas por carrapatos das espécies Amblyomma sculptum (principal vetor da FMB) e Amblyomma dubitatum, já foram identificadas nestes locais, e apesar de ocorrer picadas de carrapatos com frequência, até o momento não houve relato de casos da doença no município (QUEIROGAS et al, 2012).

Entrevistas semiestruturadas foram construídas a partir da abordagem conceitual de Conhecimentos (C), Atitudes (A) e Práticas (P) dos entrevistados, os chamados estudos CAP, que investigam o comportamento humano em relação a um tópico específico (VANDAMME, 2009). O conhecimento é o conjunto de entendimentos, a capacidade de interpretar algum tópico. A atitude é o posicionamento do indivíduo em relação a alguma situação e não está relacionado diretamente com a prática, pelo contrário, muitas vezes as atitudes não tem conexão com as práticas realizadas. A prática são ações propriamente ditas de um indivíduo em resposta a um estímulo. As seguintes perguntas foram elencadas dentro de cada grupo: A- Conhecimento: 1- Você já percebeu/viu capivara no município? O que você pensa sobre a presença delas aqui; 2- Há quanto tempo nota a presença das capivaras neste local?; 3 - Pode ter tido aumento no número e mudança na população de capivaras?; 4- Você já teve algum problema ou presenciou algum tipo de problema com as capivaras?; 5 - Você conhece o comportamento e os hábitos das capivaras?; 6 - Você já ouviu falar ou sabe que pode ocorrer infestação de carrapatos pelas capivaras?; 7 - Você sabe se as capivaras podem transmitir doenças? Se sabe fale sobre o que sabe; 8 Através de quais fontes você obteve essas informações? B - Atitudes : 1 - $O$ que você faria, ou o que você acha que deveria ser feito com as capivaras presentes neste local?; 2 - No caso de translocação, qual seria o local ideal para levar esses animais? e C- Práticas: 1 - Se presenciou algum problema com as capivaras, o que fez a respeito?; 2 - Se a presença das capivaras não traz nenhum problema, qual a sua reação diante do fato dela estar aqui neste local?

Além de características sociodemográficas dos entrevistados, como idade, sexo, profissões, escolaridade, foram pesquisadas as seguintes variáveis: Local de contato com as capivaras, vínculo com o local, tempo de vínculo, além de variáveis específicas relativas ao conhecimento, atitudes e práticas em relação às capivaras e aos possíveis danos causados por elas.

As entrevistas foram realizadas com 30 indivíduos divididos igualmente em três grupos com 10 participantes cada, a partir de sua relação com as capivaras, a saber: (i) População com contato frequente; (ii) População sem contato/contato esporádico e (iii) Poder Público.

Foram realizados quatro grupos focais, definidos no âmbito da Universidade Federal de Uberlândia e compostos por 7 a 10 indivíduos em cada grupo. A composição destes grupos foi montada para se obter grupos com retaguarda teórica com enfoques distintos sobre o problema e por isso foram constituídos da seguinte forma: pós-graduandos stricto sensu do Programa de Pós- Graduação em Ecologia e Conservação de Recursos Naturais $(n=10)$, graduandos em Medicina Veterinária $(n=10)$, graduandos em Medicina $(n=7)$ e funcionários de Serviços Gerais $(n=7)$. Foi utilizado um roteiro, também do tipo CAP, cujos tópicos embasaram a discussão proposta. 
Conhecimentos, atitudes e práticas sobre capivaras em áreas antropizadas indenes para febre maculosa: percepção da sociedade
Adalberto de Albuquerque Pajuaba Neto Jean Ezequiel Limongi Vivianne Peixoto da Silva Matias Pablo Juan Szabó

Tanto as entrevistas individuais como os grupos focais foram gravados por meio de gravador de áudio digital, transcritas na íntegra e submetidas à análise de conteúdo temático segundo Bardin $(2004)^{14}$.

Esta pesquisa foi aprovada pelo Comitê de Ética em Pesquisa da Universidade Federal de Uberlândia (Parecer $N^{\circ}$ 1.348.702/2015).

\section{RESULTADOS}

As características sociodemográficas dos entrevistados são detalhadas na tabela 1. Os entrevistados do poder público foram representados por um sargento do Corpo de Bombeiros Militar; três médicos veterinários, do zoológico municipal, da Universidade Federal de Uberlândia e do Instituto Estadual de Florestas; um advogado, promotor de justiça do Ministério Público de Minas Gerais; quatro biólogos, sendo dois da Secretaria Municipal de Meio Ambiente, um do IBAMA e um da Unidade de Vigilância em Zoonoses do município; e um sargento, da Polícia Militar do Meio Ambiente.

Tabela 1 - Características sociodemográficas dos entrevistados, estratificados por grupo.

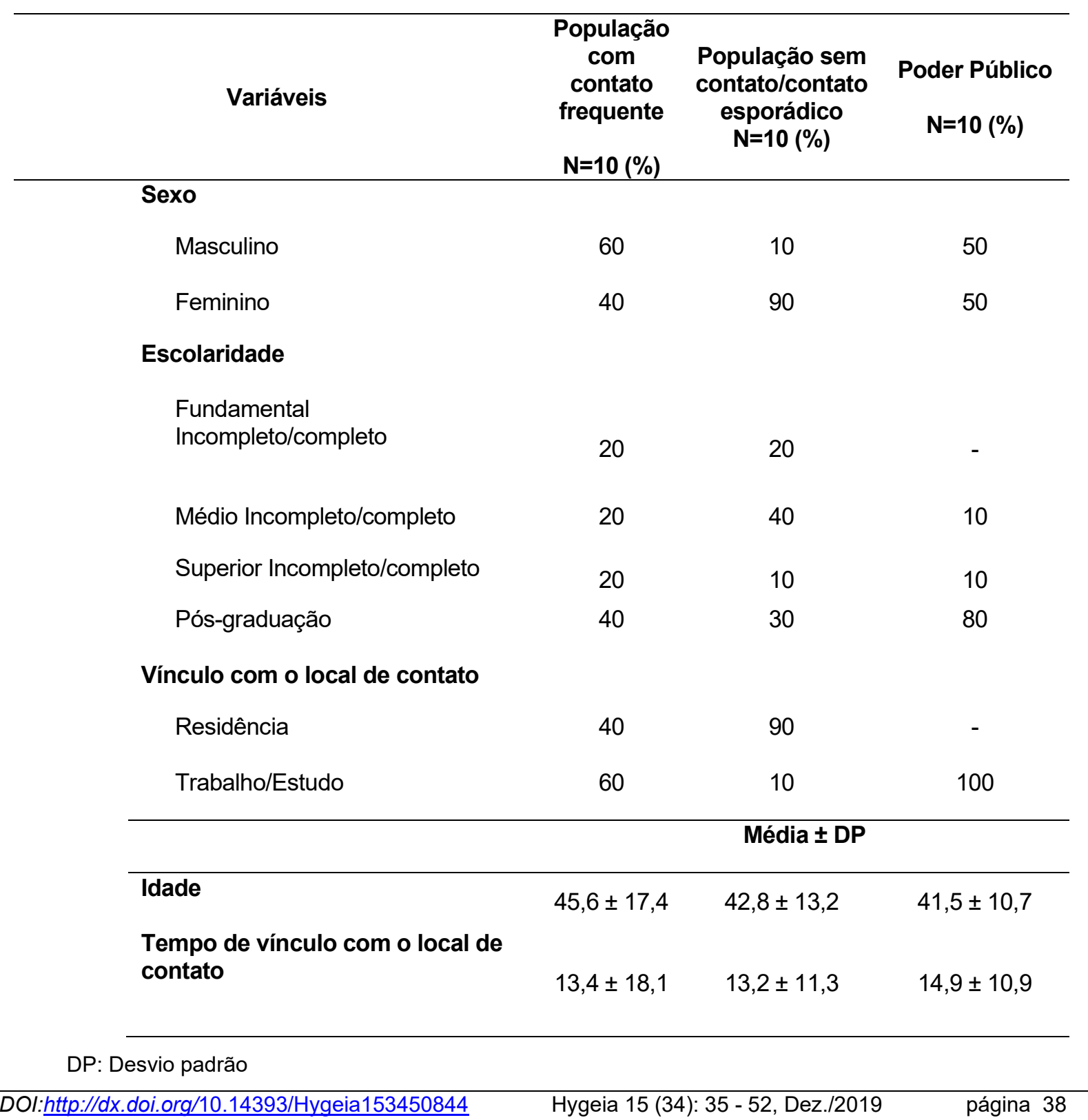


Conhecimentos, atitudes e práticas sobre capivaras em áreas antropizadas indenes para febre maculosa: percepção da sociedade
Adalberto de Albuquerque Pajuaba Neto Jean Ezequiel Limongi Vivianne Peixoto da Silva Matias Pablo Juan Szabó

A maioria dos entrevistados observou capivaras no município, mas foram os representantes do poder público que relataram a presença dos animais há mais tempo (Tabela 2). Por exemplo, um entrevistado do poder público afirmou:

"Muito mais de cinco, eu tenho 22 anos de serviços e nesses 22 anos é constante a ocorrência de capivaras, principalmente dentro do centro urbano de Uberlândia né, constante." (EPP).

Também ficou evidenciada uma percepção de aumento do número dos animais pelo poder público e grupo com contato frequente (Tabela 2).

A maioria dos representantes do poder público e do grupo com contato frequente lembrou exclusivamente da associação carrapatos e capivaras com a transmissão da febre maculosa (Tabela 2). Um entrevistado do Poder público afirmou:

[...]" quando a gente fala de capivara, eu já penso na febre maculosa né, é riquétsia, e o que eu mais sei mesmo é da parte da riquétsia mesmo, bacteriano né." (EPP).

Quando perguntados sobre o que deveria ser feito com as capivaras do município um amplo espectro de respostas foi obtido. A atitude mais frequente dos entrevistados seria deixar os animais onde estavam, porém as razões para deixar os animais no local em que se encontravam variaram. Por exemplo, um entrevistado do poder público disse:

"Isso, agora nós temos a questão da população que tem todo aquele carinho, então pra você tirar vai ter um impacto, então o que eu faria hoje? Eu deixaria." (EPP).

Tabela 2 - Conhecimentos, atitudes e práticas da população em contato frequente, população sem contato/contato esporádico e Poder Público de acordo com as entrevistas semiestruturadas sobre capivaras

\begin{tabular}{|c|c|c|c|}
\hline Variáveis & $\begin{array}{l}\text { População em } \\
\text { contato } \\
\text { frequente } \\
(N=10)\end{array}$ & $\begin{array}{l}\text { População sem } \\
\text { contato/contato } \\
\text { esporádico } \\
(\mathrm{N}=10)\end{array}$ & $\begin{array}{l}\text { Poder } \\
\text { Público } \\
(\mathrm{N}=10)\end{array}$ \\
\hline \multicolumn{4}{|c|}{ CONHECIMENTO } \\
\hline \multicolumn{4}{|l|}{$\begin{array}{l}\text { Você já percebeu/viu capivara no } \\
\text { município? }\end{array}$} \\
\hline Sim & 10 & 1 & 9 \\
\hline Não & 0 & 9 & 0 \\
\hline Não respondeu & 0 & 0 & 1 \\
\hline \multicolumn{4}{|l|}{$\begin{array}{l}\text { Há quanto tempo nota a presença das } \\
\text { capivaras? }\end{array}$} \\
\hline Nunca viu & 0 & 7 & 0 \\
\hline 1 a 5 anos & 7 & 1 & 3 \\
\hline 6 a 10 anos & 2 & 1 & 3 \\
\hline$>10$ anos & 1 & 1 & 4 \\
\hline \multicolumn{4}{|l|}{$\begin{array}{l}\text { Pode ter tido aumento no número e } \\
\text { mudança na população de capivaras? }\end{array}$} \\
\hline Sim & 9 & 2 & 9 \\
\hline Não & 1 & 5 & 0 \\
\hline Não sabe & 0 & 3 & 1 \\
\hline \multicolumn{4}{|l|}{$\begin{array}{l}\text { Você já teve algum problema ou } \\
\text { presenciou algum tipo de problema com } \\
\text { as capivaras? }\end{array}$} \\
\hline Sim & 5 & 1 & 5 \\
\hline Não & 5 & 9 & 5 \\
\hline $\begin{array}{l}\text { Você conhece o comportamento e os } \\
\text { hábitos das capivaras? }\end{array}$ & & & \\
\hline
\end{tabular}


Conhecimentos, atitudes e práticas sobre capivaras em áreas antropizadas indenes para febre maculosa: percepção da sociedade
Adalberto de Albuquerque Pajuaba Neto Jean Ezequiel Limongi Vivianne Peixoto da Silva Matias Pablo Juan Szabó

\section{Sim}

Não

Não respondeu

Você já ouviu falar ou sabe que pode ocorrer infestação de carrapatos pelas capivaras?

Sim
Não
Não respondeu

$\begin{array}{lll}5 & 2 & 9 \\ 4 & 8 & 1 \\ 1 & 0 & 0\end{array}$

$8 \quad 4 \quad 10$

$0 \quad 6 \quad 0$

200

Você sabe se as capivaras podem transmitir doenças?

\begin{tabular}{lrrr} 
Sim & 9 & 3 & 9 \\
Não & 1 & 7 & 1 \\
\hline & ATITUDE & & \\
\hline O que você pensa sobre a presença & & & \\
delas aqui? & & 0 & 2 \\
Incomoda & 5 & 6 & 0 \\
Não incomoda/lndiferente & 4 & 4 & \\
Não respondeu & 1 & &
\end{tabular}

Se presenciou ou presenciaria algum

problema com as capivaras, o que

fez/faria a respeito?

Espanta

Não espanta

Não respondeu

Já fez ou recebe algum tipo de

reclamação, investigação ou

comunicação ao órgão responsável?

Sim

Não

Você faria alguma coisa para impedir o

9

$\begin{array}{lll}3 & 1 & 1 \\ 7 & 7 & 4 \\ 0 & 2 & 5\end{array}$

acesso dessas capivaras?

Sim

4

6

Não respondeu

Se a presença das capivaras não traz nenhum problema, qual a sua reação diante do fato dela estar aqui neste local?

Observação

Indiferença

Não respondeu

$\begin{array}{ccc}1 & 0 & 8 \\ 9 & 10 & 2\end{array}$

8

2

$\begin{array}{ccc}0 & 2 \\ 10 & 7 \\ 0 & 1\end{array}$

Quando confrontados com a necessidade de translocação e definir o destino das capivaras, novamente uma ampla gama de respostas foi obtida. Quatro representantes do poder público foram categoricamente contra a translocação, mas com dificuldades em sugerir alternativa, por exemplo:

[...]" translocar capivara é uma coisa que eu não recomendo e se hipoteticamente houvesse a possibilidade, animais livres de doença, enfim, em outras condições, eu ainda acho a translocação uma medida que não resolve nada." (EPP)

A interpretação dos resultados das entrevistas por meio de inferência dos dados e das categorias após a pré-análise, codificação, classificação e categorização do material, está apresentada na Tabela 3. 
A relação entre os sentimentos associados às capivaras e o ser humano nos grupos focais são detalhadas nas tabelas 4 e 5 .

Os auxiliares de serviços gerais representaram o grupo com menor grau de escolaridade e demonstraram receio em expor suas opiniões.

No que tange à relação afetiva, todos consideraram a capivara um animal carismático e inofensivo (Tabela 4), como expresso na fala:

[...] "sempre achei ela linda, aquele pelo parece macio né." (E1)

O grupo focal de graduandos de medicina veterinária foi caracterizado por contraste de atitudes e de percepções sobre capivaras (Tabela 4). O carisma da capivara ficou evidente em algumas colocações como pode ser percebido pelas falas:

[...] " eu acho bonito." (E 5)

Outros a consideram uma fonte de alimento:

[...] “ A carne delas é bem apreciada né?”(E 9)

Notou-se ainda expressões de desagravo direto:

[...] "acho que tem que ir matando, igual pombo."(E 9)

Quanto a problemas relacionados às capivaras esse grupo demonstrou conhecimento sobre carrapatos, febre maculosa e outros:

[...] "lá tava dando muito carrapato e teve gente que pegou Febre Maculosa. (E 2).

Neste grupo focal houve uma percepção sobre superpopulação na área urbana, notadamente nos últimos 10 anos:

"Mas o pior é que não tem controle da população, a gente vê que tem muita, muita capivara e não tem controle."(E 8)

E a necessidade de um controle populacional ou destino do excedente de animais:

"Transportar elas de volta para um habitat natural delas né, ou parecido com o que elas estão acostumada a viver"(E 6)

Segundo alguns componentes deste grupo, o poder público, sem especificar quem do poder público, deveria ser responsável pelo manejo das capivaras e problemas associados:

[...] "também com o poder público atuando e transportando essas capivaras pro habitat natural delas (E 6)

Os mestrandos em Ecologia e Conservação de Recursos Naturais abordaram aspectos semelhantes aos dos outros grupos focais, mas discutiram o possível manejo de capivaras em profundidade maior.

Reconhecem o problema do carrapato e febre maculosa assim como outros motivos de conflito:

[...] "mas ela carrega o carrapato estrela, então às vezes ele tá contaminada de febre maculosa, então já aconteceu de em parques públicos, no caso do Horto Florestal de São Paulo" (E 6)

Este grupo discutiu também a necessidade de controle e manejo das populações de capivaras, em especial a translocação, mas lembraram de que é importante um estudo prévio das populações e dos problemas associados:

"Acho que mais básico inicialmente seria levantar as populações, pelo menos conhecer as populações de cada área urbana que sabe que tem uma ocorrência grande de capivara."(E 3)

Igualmente ao grupo anterior, um participante também considerou o ser humano um vilão, a capivara uma vítima:

"É, eu acho que o problema de ações de manejo geralmente é que sempre quem paga o pato é o organismo que você vai manejar." 
Tabela 3 - Categorias Temáticas construídas a partir das entrevistas com os participantes do estudo, distribuídos por grupos: população em contato frequente (CF), População sem contato/contato esporádico (CE) e Poder Público (PP).

\begin{tabular}{|c|c|c|c|}
\hline Participantes da pesquisa & Relação afetiva entre o ser humano e a capivara & $\begin{array}{l}\text { Fontes de } \\
\text { informação } \\
\text { para a } \\
\text { construção do }\end{array}$ & Práticas baseadas no entendimento das políticas públicas \\
\hline $\begin{array}{l}\text { População em contato } \\
\text { frequente (CF) }\end{array}$ & $\begin{array}{l}\text { Os entrevistados afirmam saber da existência de capivaras há mais de um ano } \\
\text { na cidade, no entanto, demonstraram pouco ou nenhum conhecimento sobre } \\
\text { seus hábitos, apesar de saber sobre a relação existente entre a presença de } \\
\text { carrapatos e transmissão de doenças, com exceção de um entrevistado. A } \\
\text { relação afetiva estabelecida entre o ser humano e a capivara neste grupo de } \\
\text { participantes do estudo, mostrou-se mais harmoniosa e protecionista, embora } 4 \\
\text { participantes relataram preocupação com os problemas trazidos pelas } \\
\text { capivaras. }\end{array}$ & $\begin{array}{l}\text { TV } \\
\text { Informação de } \\
\text { terceiros } \\
\text { Internet } \\
\text { Livros } \\
\text { cientíicos } \\
\text { Estudos } \\
\text { Rotina de } \\
\text { trabalho }\end{array}$ & $\begin{array}{l}\text { Os entrevistados disseram ser indiferentes diante das capivaras, apesar de } \\
\text { preocuparem com os carrapatos. Em seus relatos, um entrevistado acionaria a } \\
\text { Polícia Florestal, acreditando ser este o órgão responsável por práticas de } \\
\text { manejo das capivaras, dois entrevistados espantariam os animais caso } \\
\text { estivessem próximos de suas casas e/ou em vias públicas e quatro dos } \\
\text { entrevistados usariam cercas para impedir o acesso. Com exceção de um dos } \\
\text { entrevistados, que sinalizou a prática do sacrifício das capivaras, como fonte de } \\
\text { alimentos, os outros entrevistados se posicionaram de forma passiva quanto ao } \\
\text { local de permanência das capivaras, com indicação de castração de machos e } \\
\text { estudos para controle desta população, indicação de outros locais, como: } \\
\text { fazenda, reserva ou zoológico, desde que tenham boas condições de } \\
\text { alimentação. }\end{array}$ \\
\hline $\begin{array}{l}\text { População sem } \\
\text { contato/contato esporádico } \\
\text { (CE) }\end{array}$ & $\begin{array}{l}\text { Os entrevistados relatam nunca ter visto capivara, com exceção de um. Não } \\
\text { souberam opinar sobre os hábitos, mudanças na população de capivaras e } \\
\text { problemas relacionados a elas. Porém, três entrevistados mencionaram a } \\
\text { possibilidade de infestação por carrapatos e ocorrência de doença transmitida } \\
\text { por ele. }\end{array}$ & $\begin{array}{l}\text { TV } \\
\text { Informação de } \\
\text { terceiros } \\
\text { Faculdade }\end{array}$ & $\begin{array}{l}\text { Os entrevistados demonstram ser indiferentes à presença das capivaras na } \\
\text { cidade e não fariam nada para impedir seu acesso. Em caso de problema } \\
\text { acionariam a Zoonoses ou o Corpo de Bombeiros, por entender serem estes os } \\
\text { órgãos responsáveis para tomada de atitudes. Com exceção de um dos } \\
\text { entrevistados, que sinalizou a prática do sacrifício das capivaras, como fonte de } \\
\text { alimentos caso estivessem na zona rural, e outro que se manifestou a favor de } \\
\text { eutanásia para as doentes, os outros entrevistados se posicionaram de forma } \\
\text { passiva quanto ao local de permanência das capivaras, com indicação de } \\
\text { castração, outros levariam para matas, fazendas, beira de represa, rio e } \\
\text { zoológico }\end{array}$ \\
\hline Poder Público (PP) & $\begin{array}{l}\text { Os entrevistados relatam a presença das capivaras há mais de cinco anos, } \\
\text { acham que a população aumentou por esses animais se sentirem mais à } \\
\text { vontade junto à população, pelo comportamento humano. Dentre os problemas } \\
\text { relatados com capivara citam a agressão, invasão de residências, infestação de } \\
\text { carrapato, atropelamento e a morte das capivaras pelo ser humano. A maioria } \\
\text { dos entrevistados tem conhecimento a respeito das capivaras, com exceção de } \\
\text { um, mas, dentre os que possuem, o mesmo não se mostra aprofundado como } \\
\text { esperado para esta categoria. Todos sabem da infestação de carrapatos e da } \\
\text { transmissão da doença, e dois citam a presença da riquétsia. }\end{array}$ & $\begin{array}{l}\text { TV } \\
\text { Veterinários } \\
\text { Rádio } \\
\text { Zoonoses e } \\
\text { Zoológico }\end{array}$ & $\begin{array}{l}\text { A maioria dos entrevistados já presenciou ou teve problemas com capivaras e os } \\
\text { que não tiveram diretamente receberam reclamações nos órgãos onde atuam. } \\
\text { Porém, a maioria mostrou-se indiferente à presença delas, exceto um que } \\
\text { espantaria sem causar stress para o animal. Todos relatam necessidade de } \\
\text { maior atuação dos órgãos ambientais municipais, estaduais e federais com } \\
\text { relação à presença das capivaras no meio urbano para além do IBAMA e da } \\
\text { Política Federal. Como formas de controle, relataram vasectomia, castração } \\
\text { química, manejo adequado e se necessário a eutanásia. Alguns são contra a } \\
\text { translocação das capivaras, inclusive por já ter criado um laço afetivo entre o } \\
\text { animal e a população e, outros levariam para áreas de preservação permanente, } \\
\text { criatórios comerciais e áreas que não tenham contato com a população. }\end{array}$ \\
\hline
\end{tabular}


Conhecimentos, atitudes e práticas sobre capivaras em áreas antropizadas indenes para febre maculosa: percepção da sociedade
Adalberto de Albuquerque Pajuaba Neto Jean Ezequiel Limongi Vivianne Peixoto da Silva Matias Pablo Juan Szabó

Quanto à atitudes esse grupo vê a necessidade de um controle populacional das capivaras embora a forma seja incerta:

"Sabe, eu acho que pode existir um controle populacional, agora como isso vai ser feito, aí eu não sei, tem que ter controle populacional."(E 5)

O Grupo focal dos graduandos em Medicina foi caracterizado por percepções e atitudes mais objetivas e centradas sobre a saúde humana. Esse grupo focal, à semelhança dos outros, considerou a capivara um animal carismático:

[...] "gosto do jeito que Curitiba trata as capivaras, assim eles tem uma página no facebook, assim as capivaras é tipo assim meio que símbolo da cidade, tem bichinho de pelúcia das capivaras."(E7).

Tabela 4 - Distribuição dos dados quanto aos sentimentos associados entre o ser humano e a capivara, por associação de palavras e frequência.

\begin{tabular}{|c|c|c|}
\hline Grupos Focais & $\begin{array}{c}\text { Sentimentos } \\
\text { associados às } \\
\text { capivaras pelos } \\
\text { participantes }\end{array}$ & Ocorrência \\
\hline \multirow{6}{*}{$\begin{array}{l}\text { Pós-graduandos em Ecologia e Conservação de Recursos } \\
\qquad \text { Naturais }(n=10)\end{array}$} & Indiferença & 3 \\
\hline & Carinho & 4 \\
\hline & Rejeição & 2 \\
\hline & Proteção & 9 \\
\hline & Medo & 0 \\
\hline & Caça/alimentação & 1 \\
\hline \multirow{6}{*}{ Graduandos em Medicina $(n=7)$} & Indiferença & 2 \\
\hline & Carinho & 3 \\
\hline & Rejeição & 4 \\
\hline & Proteção & 5 \\
\hline & Medo & 1 \\
\hline & Caça/alimentação & 1 \\
\hline \multirow{6}{*}{ Graduandos em Medicina Veterinária $(n=10)$} & Indiferença & 3 \\
\hline & Carinho & 4 \\
\hline & Rejeição & 10 \\
\hline & Proteção & 9 \\
\hline & Medo & 0 \\
\hline & Caça/alimentação & 2 \\
\hline \multirow{6}{*}{ Auxiliares de Serviços Gerais $(n=8)$} & Indiferença & 2 \\
\hline & Carinho & 4 \\
\hline & Rejeição & 1 \\
\hline & Proteção & 5 \\
\hline & Medo & 0 \\
\hline & Caça/alimentação & 2 \\
\hline
\end{tabular}


Conhecimentos, atitudes e práticas sobre capivaras em áreas antropizadas indenes para febre maculosa: percepção da sociedade
Adalberto de Albuquerque Pajuaba Neto Jean Ezequiel Limongi Vivianne Peixoto da Silva Matias Pablo Juan Szabó

Tabela 5 - Relação entre os sentimentos associados às capivaras e as práticas baseadas no entendimento dos participantes sobre as políticas públicas.

\begin{tabular}{|c|c|c|}
\hline $\begin{array}{l}\text { Grupos } \\
\text { Focais }\end{array}$ & $\begin{array}{l}\text { Sentimentos } \\
\text { Associados }\end{array}$ & $\begin{array}{l}\text { Práticas } \\
\text { (individuais e/ou de políticas públicas) }\end{array}$ \\
\hline \multirow{3}{*}{$\begin{array}{l}\text { Pós- } \\
\text { graduandos } \\
\text { em Ecologia } \\
\text { e } \\
\text { Conservação } \\
\text { de Recursos } \\
\text { Naturais } \\
(n=10)\end{array}$} & Afetividade & $\begin{array}{l}\text {-convivência fácil } \\
\text {-passividade dos animais } \\
\text {-transmitem simpatia } \\
\text {-admirar } \\
\text {-capacidade de interação com outros animais }\end{array}$ \\
\hline & Rejeição & $\begin{array}{l}\text {-indiferença } \\
\text {-ataque } \\
\text {-manter distância } \\
\text {-albergar o carrapato estrela } \\
\text {-transmissão da Febre maculosa }\end{array}$ \\
\hline & Proteção & $\begin{array}{l}\text {-controle sanitário e populacional } \\
\text {-manejo adequado } \\
\text {-legislação específica para proteção da espécie (federal, estadual } \\
\text { e/ou municipal) } \\
\text {-programas de controle por esterilização } \\
\text {-controle preventivo de atropelamentos e predadores } \\
\text {-caça ilegal }\end{array}$ \\
\hline \multirow{3}{*}{$\begin{array}{c}\text { Graduandos } \\
\text { em Medicina } \\
(n=7)\end{array}$} & Afetividade & $\begin{array}{l}\text { - passividade dos animais } \\
\text {-transmitem simpatia } \\
\text {-são tratadas como símboloem Curitiba } \\
\text {-indiferença } \\
\text { - liberação da caça como alternativa para controle da população de } \\
\text { capivaras }\end{array}$ \\
\hline & Rejeição & $\begin{array}{l}\text {-conscientização da população sobre os riscos que as capivaras } \\
\text { causam } \\
\text {-alerta sobre os acidentes no trânsito urbano devido à presença de } \\
\text { capivaras } \\
\text {-transmitem a Febre maculosa } \\
\text {-destruição de lavouras } \\
\text {-retirar as capivaras do convívio social } \\
\text {-liberação da caça para subsistência para população de baixa renda } \\
\text {-liberação da caça esportiva } \\
\text {-medo }\end{array}$ \\
\hline & Proteção & $\begin{array}{l}\text {-alimentar as capivaras } \\
\text {-programas de controle sanitário de conscientização } \\
\text {-evitar a invasão de seu habitat pelos homens-cercar os espaços que } \\
\text { as capivaras ocupam, promovendo a proteção delas e dos homens, } \\
\text { pela prevenção do contato. } \\
\text {-deve ter um local adequado para que as capivaras não provoquem } \\
\text { acidentes } \\
\text {-controle populacional } \\
\text {-animal como lazer } \\
\text {-promoção de cuidados através do Hospital Veterinário } \\
\text {-reintroduçãodas capivaras no ambiente silvestre }\end{array}$ \\
\hline
\end{tabular}




\section{Graduandos em Medicina Veterinária $(n=10)$}

\section{Afetividade - animal bonito e inofensivo -adotar como animal de estimação}

Rejeição -animal feio

-indiferença

-problemassanitários com carrapatos

- forte odor liberado pelas capivaras

- evitar contato com capivaras

-falta de controle populacional

- liberação da caça para subsistência para população de baixa renda -eliminaras capivaras da cidade

-medo de aproximar

Proteção -programas educativos para diminuir os atropelamentos

-cuidar dos animais que estão na cidade

-cuidar e preservar o ambiente das capivaras

-uso de carrapaticidas para controle de infestações de artrópodes

nas capivaras

-programas de castração como alternativa para o abate das

capivaras e controle populacional

-reintroduçãodas capivaras no ambiente silvestre

\begin{tabular}{cll}
\hline & Afetividade & $\begin{array}{l}\text {-animal bonito, pelo macio } \\
\text { - manso, inofensivo } \\
\text {-adotar como animal de estimação } \\
\text {-faria um registro fotográfico com o celular }\end{array}$ \\
$\begin{array}{c}\text { Auxiliares de } \begin{array}{c}\text { Serviços } \\
\text { Gerais }(\mathbf{n = 8})\end{array} \\
\text { Rejeição }\end{array}$ & $\begin{array}{l}\text {-destroem lavouras } \\
\text {-causam danos na zona rural } \\
\text {-carrapatos causam doenças }\end{array}$ \\
& Proteção & $\begin{array}{l}\text {-preocupação com o abate de capivaras } \\
\text {-com a destruição do seu habitat } \\
\text {-levar a capivara para um lugar adequado através do IBAMA }\end{array}$ \\
\hline
\end{tabular}

\section{DISCUSSÃO}

Em um passado mais recente da evolução, a relação com outros animais se modificou com a aproximação entre aqueles que seriam os cães domésticos e o ser humano. Esta aproximação iniciada há aproximadamente 12.000 anos e com características iniciais de sinantropia também mudou a evolução das duas espécies envolvidas (LARSON; FULLER, 2014). llustram essa revolução, os dados do IBGE que demonstram um número maior de famílias no Brasil com "pets" (52,2 milhões de cães e 22,1 milhões de gatos) quando comparados ao número de crianças até 14 anos (44,9 milhões) (BRASIL, 2015). Associada primordialmente à modificação ambiental de origem antrópica surgiram os animais sinantrópicos. Estas espécies são aquelas que foram acidentalmente beneficiadas pelas condições ambientais criadas pela atividade humana e passaram a habitar ecossistemas urbanos ou antropizados independentemente da vontade do ser humano. O maior número de espécies animais, porém, são aqueles denominados de selvagens e que vivem na dependência de ambientes prístinos, muitos em risco de extinção pela dizimação do seu habitat natural (ANDRIOLA et al, 2013). Embora as categorias de animais possam ser discriminadas, elas são dinâmicas e frequentemente com intersecções. De fato, pode haver sobreposições de categorias, trânsito de animais entre categorias e, o que causa conflitos na sociedade e percepções diferentes na 
classificação dos animais pelos seres humanos. Animais domésticos e "pets" podem sofrer uma reversão selvagem como é o caso de gatos asselvajados e o porco monteiro (MC CARTHY; LEVINE; REED, 2013; DESBIEZ et al, 2011). Animais selvagens podem ser utilizados como animais de produção como é o caso das capivaras ou animais de laboratório como é o caso de primatas não humanos (PINHEIRO; MOREIRA, 2013; GUIRAKHOO et al, 2004). Ainda, animais selvagens podem se tornar "pets" como é o caso de cobras (SMEETS et al, 1991). As percepções diferentes acontecem pela relação diversa com animais que existe entre indivíduos de uma mesma sociedade e, frequentemente, entre o poder público e indivíduos. Importante ressaltar que não há, a saber, uma quantificação desses conflitos, mas parecem estar em franca expansão conforme se desprende da necessidade crescente por legislação específica para tratamento humanitário de animais.

Uma situação que ilustra os conflitos acima mencionados é o da capivara em áreas urbanas e rurais. Nas últimas décadas as capivaras se tornaram um dos três maiores protagonistas dos conflitos animal selvagem-humanos no Brasil (MARCHINI; CRAWSHAW, 2015). Em áreas antropizadas são favorecidos pelo ambiente com água e alimentação abundante, mas expostos a adversidades, como acidentes com veículos (atropelamentos), afogamento em piscinas, desenvolvimento de doenças decorrentes da elevada densidade populacional e do contato com animais domésticos, sinantrópicos e com o ser humano, predação por matilhas de cães asselvajados e caça (MOREIRA; PIOVESAN, 2005). Por outro lado, diversos prejuízos são atribuídos às capivaras em áreas antropizadas (MOREIRA; PIOVESAN, 2005; FERRAZ et al, 2003; VERDADE; FERRAZ, 2006; FELIX et al, 2014). Dentre os problemas se destacam danos às plantações, invasão de propriedades com acúmulo de fezes, destruição de plantas ornamentais e uso de piscinas, acidentes de trânsito e em ocasiões mais raras, agressividade a humanos e animais domésticos. Além do mais, são animais associados às infestações parasitárias e potencial transmissão de doenças para outros animais e ao ser humano. Dentre estes, a manutenção de grandes populações de carrapatos e consequentes picadas e, em alguns locais, a transmissão da Febre maculosa brasileira são as mais preocupantes (LABRUNA, 2009). Há de se mencionar a este respeito a crescente urbanização da Febre Maculosa associada ao estabelecimento de populações de capivaras e infestações ambientais por carrapatos em cidades (QUEIROGAS et al, 2012; NASSER et al, 2015).

Os problemas envolvendo capivaras têm gerado conflitos entre a sociedade civil, organizada ou não, e o poder público. É dever do poder público preservar a saúde humana, mas a sociedade, pelo menos segmentos desta, exige preservar também as capivaras. Estes conflitos se repetem em vários municípios, mas as atitudes, dificuldades, erros e eventuais soluções muitas vezes permanecem sem registro, análise e/ou divulgação adequados. Com isso cada município tende a enfrentar o problema individualmente e à mercê de pressões momentâneas em um misto de emoções, impressões, experiências individuais ou de pequenos grupos, ou ainda de interesses políticos diversos, sem um embasamento técnico adequado. As situações tendem a ser divulgadas pela imprensa, quando ultrapassam um limiar de interesse, gerada em geral por um problema agudo como a morte de um cidadão por febre maculosa. Ultrapassado esse limiar e com a divulgação pela imprensa, surgem as pressões sobre o poder público por uma ação imediata e que deriva em uma série de práticas desconexas e com eficácia questionável. Um exemplo recente de conflitos, com sequência de decisões e práticas conflitantes entre si, foi observado na lagoa da Pampulha em Belo Horizonte (BBC BRASIL, 2016). Neste local há óbitos humanos por febre maculosa e a bactéria foi recentemente isolada de um carrapato (LABRUNA et al, 2017). Deflagrada uma urgência de tomada de atitude pelo poder público após a morte de um munícipe, capivaras foram retiradas do local e mantidas em recintos. Constatou-se posteriormente que a sanidade dos animais foi prejudicada no cativeiro e a soltura deles foi decretada retornando-se à situação inicial após, entre outros, judicialização do problema e morte de animais. De fato, as atitudes tomadas foram imediatistas e pautadas pela pressão de segmentos da sociedade. Neste conflito a ausência de política pública bem definida e norteadora das ações foi proeminente e as emoções, imediatismo e crenças individuais dominaram as tomadas de decisão.

O Estado de São Paulo se constitui em exceção a essa situação, com a atuação da Superintendência de Controle de Endemias (SUCEN) e a Secretaria do Meio Ambiente do Estado, dispõem de política pública e órgãos de referência para atuação e coordenação de ações envolvendo carrapatos, capivaras e febre maculosa (SÃO PAULO, 2016). Há uma normatização de caráter geral e com atribuição de responsabilidades sobre o manejo de capivaras quando relacionado ao risco à saúde 
pública pela FMB. Porém, ainda assim a relação da sociedade ou segmentos dessa com as políticas adotadas é frequentemente conflituosa e a política pública é constantemente questionada, desafiada e/ou desobedecida. De fato, toda política pública deve considerar aspectos técnicos, mas também a percepção da sociedade sobre o assunto, sob a pena de desobediência civil. Esse procedimento é fundamental para entender a relação da sociedade com o problema, e permitir a discussão, posteriormente a comunicação das atitudes adotadas para que sejam bem fundamentadas, inteligíveis, transparentes, tendo a sociedade como avalista e colaboradora na sua implementação e aplicação.

A abordagem conceitual do tipo CAP, aplicada neste estudo, permitiu ordenar as questões das entrevistas de forma a posicionar os entrevistados em uma linha de raciocínio que considerasse a experiência de cada indivíduo sem impedir as manifestações espontâneas. Compreender os níveis de conhecimento, atitudes e práticas de uma população permite uma abordagem mais eficiente no processo de sensibilização, uma vez que os programas de promoção e prevenção de saúde podem ser adaptados de forma mais adequada à necessidade da comunidade (KALIYAPERUMAL, 2004). Esta abordagem parte do pressuposto de que um comportamento em saúde está ligado a um processo sequencial que se origina na aquisição de um conhecimento cientificamente correto, que pode explicar a formação de uma atitude favorável e a adoção de uma prática de saúde pertinente (BRICENO-LEON, 1996). O comportamento é genericamente explicado por meio de duas grandes correntes teóricas: uma defende que as pessoas atuam pelas circunstâncias, pela situação; outra diz que as pessoas atuam por seus valores e suas crenças (GILLETT, 1985). O modelo CAP é baseado nesta segunda teoria.

Notou-se nas entrevistas, uma diferença muito grande nos conhecimentos atitudes e práticas em relação às capivaras entre os três grupos de entrevistados. Porém a experiência individual de cada entrevistado foi decisiva em estabelecer profundas diferenças nas percepções também dentro de cada grupo.

Considerando em conjunto todas as informações e discussões das entrevistas e grupos focais e abstraindo as posturas mais isoladas, alguns aspectos comuns devem ser ressaltados para que possam ser considerados em políticas públicas. As capivaras são uma realidade assaz presente, mas que afetam as pessoas de forma dissimilar. Em um extremo estão aqueles mais desinteressados pela experiência reduzida ou inexistente e do outro lado aqueles com envolvimento maior dado pelo contato e experiências vividas (incluindo o poder público). Aqueles com contato expressam percepções diversas de acordo com as experiências pessoais, complementadas pelas informações recebidas principalmente pela televisão e/ou por terceiros. As percepções mostram que a capivara é um animal carismático, pelo aspecto bonito e inofensivo, e cuja visão gera bem-estar e sensação de contato com a natureza. Essa percepção é, provavelmente, compartilhada em diversos outros municípios como é o caso de Curitiba que escolheu a capivara como animal símbolo da cidade (BEM PARANÁ, 2015). Por outro lado, alguns indivíduos e o poder público experenciam problemas com capivaras, manifestado pela destruição de hortas, atropelamentos dos animais, picadas de carrapatos e temor da infecção humana pela febre maculosa. Porém, mesmo entre aqueles que vivenciam os problemas surge uma ambiguidade de sensações dada pelos problemas causados de um lado e o carisma do animal do outro. Há de se ressaltar que o carisma pode ter um efeito mais complexo sobre aqueles que experienciam os problemas; um conflito pessoal dado por gostar do animal, mas que é associado a problemas ou ainda temor de que atitudes para solucionar os problemas possam afetar de forma negativa as capivaras e despertar uma reação da sociedade ou do poder público.

No caso do poder público notou-se um dilema entre o indivíduo e do ser humano público, das necessidades individuais contrastando com aquelas de responsabilidade do cargo. Na ausência de uma política pública bem definida com critérios claros e tecnicamente justificáveis, percepções, atitudes e práticas foram desorientadas, e seguindo uma cartilha de construção individual. Esta cartilha baseada em critérios técnicos fragmentados e/ou precários, em alguns casos subordinados à crenças e moral individual, foi exposta mais para justificar os próprios atos, do que para solução do problema. Decorrente disso, em caso de problemas, as pessoas se defrontam com esquivas, atitudes desmedidas, frequentemente imediatistas e principalmente desarticuladas entre os representantes do poder público. Como consequência surgem, a desconfiança, a resignação com o 
problema e procura por soluções próprias, de forma mais nefasta, ausência de credibilidade no poder público, base para a desobediência civil.

Uma outra percepção muito relevante para atitudes e práticas com capivaras se fez presente entre muitos entrevistados e todos os grupos focais. Trata-se de uma sensação de culpa que se sente em relação ao animal. Este sentimento é baseado na noção equivocada, de que o ser humano ao destruir o ambiente, tomou o lugar das capivaras e os animais procuram refúgios em cidades. Embora as razões por este sentimento exijam por si só um estudo antropológico e psicológico, específicos, podemos sugerir que a culpa advenha do antropomorfismo das capivaras. Nessa percepção os animais estariam se aglomerando em locais específicos das cidades ao fugirem dos habitats destruídos ou ainda retornando ao local de origem à semelhança de refugiados humanos. Merece menção aqui que a interpretação técnica para o aumento do número de capivaras em áreas urbanas e rurais está mais relacionada ás modificações ambientais humanas que favoreceram acidentalmente estes animais de forma similar à que ocorreu com outros animais sinantrópicos. As modificações cruciais neste contexto foram entre outros, o estabelecimento de coleções hídricas onde antes não existiam, disponibilidade aumentada de alimentação e diminuição da predação pelo ser humano e outros predadores (MARCHINI; CRAWSHAW, 2015; VERDADE; FERRAZ, 2006; CAMPOS-KRAUER; WISELY, 2011). De fato, a densidade e a biomassa de capivaras podem ser muito maiores em áreas antropizadas do que em locais prístinos e estão presentes em ambientes que não suportariam populações de capivaras antes das modificações ambientais antrópicas (VERDADE; FERRAZ, 2006; LABRUNA et al, 2017; CAMPOS-KRAUER; WISELY, 2011).. Portanto, no caso específico das capivaras em áreas urbanas, usando uma alcunha antrópica, o termo "invasão" seria mais apropriado que "refugiado". Em sendo assim, essa percepção de muitos dos entrevistados se baseou em um fato (aumento no número de capivaras), mas foi essencialmente de fundo emocional e que levou à interpretação equivocada das causas desse aumento.

Ligado a essa sensação de culpa dos seres humanos está a atitude e, infelizmente, a prática frequente, de translocação dos animais problema de áreas urbanas. Esta translocação tem como base o forte apelo emocional desta prática e que foi mencionada de forma recorrente nas entrevistas e grupos focais. Trata-se da sensação de que existe um local muito melhor para os animais e no qual o bem-estar deles estaria assegurado; uma associação entre a soltura e "retorno ao lar". A definição desse local de destino é vaga na mente da maioria, mas se traduz principalmente em áreas de proteção ambiental. Esta prática, apesar de reconhecida por vários representantes do poder público como inadequada, está associada a um reforço positivo frequente dada pelas imagens na televisão de soltura de animais selvagens. No entanto, essa prática resulta mais provavelmente na morte dos animais soltos ou desiquilíbrios ecológicos no local de soltura (RODRIGUES, 2006).

Relacionada à opção de manter as capivaras problema nas áreas urbanas de origem ou ainda, destinar à translocação, entrevistados do poder público e dos técnicos em formação dos grupos focais, ressaltaram a necessidade de avaliação sanitária dos animais. Embora tal avaliação revesta essas opções de um caráter técnico, expõe a tentativa de aplicação de procedimentos gerais de saúde pública e sanidade animal, sobre um problema específico, com características próprias e, portanto, não têm embasamento teórico que a sustente. Conforme revisto por Cueto (2013) as informações sobre agentes patogênicos associados a capivaras são incipientes e mais relacionadas às populações cativas. De fato, pouco se sabe sobre patógenos de capivaras em vida livre. Além disso, esses animais podem albergar patógenos sem manifestar doenças, como é o caso de Rickettsia rickettsii causador da febre maculosa humana e Trypanossoma evansi (CUETO, 2013; SOUZA et al, 2009). Segundo Cueto (2013), daqueles patógenos já estudados nesses animais, capivaras poderiam transmitir para outros animais, entre outros, raiva, leptospirose, brucelose e febre aftosa, mas a importância deles na cadeia epidemiológica é desconhecida. Deve-se também considerar, outros patógenos, ainda desconhecidos, que esses animais possam albergar e finalmente o custo e capacidade técnica para as avaliações (captura, coleta de amostras e técnicas laboratoriais para os diversos agentes). Em resumo, não há uma avaliação sanitária geral disponível para esses animais que sustente uma translocação ou manutenção no local isenta de riscos sanitários, um fato que precisa estar explícito em todas as discussões sobre o problema e exposto claramente para a sociedade. 
Enfim, nota-se que apesar das variações entre indivíduos e grupos, as percepções expostas neste trabalho são a resultante da mescla de informações provenientes da televisão, de terceiros, de outros meios de comunicação e emoções emanadas por um animal carismático e um antropomorfismo muito prevalente na sociedade. As informações, ainda que mais precisas e técnicas no caso do poder público e grupos de técnicos em desenvolvimento, são preponderantemente vagas e/ou fragmentadas, em alguns casos conflitantes. Considerando que a solução dos conflitos com capivaras em áreas urbanas e rurais envolve a avaliação técnica das situações, descrição da realidade e baseado nesta, a confecção de propostas de práticas a serem escolhidas e aceitas pela sociedade, as informações disponibilizadas deveriam ser reais, desprovidas de maquiagens. A sociedade tem o direito de conhecer a realidade para poder avaliar e decidir sobre ônus e bônus de cada prática proposta. É neste contexto que o antropomorfismo se torna um obstáculo para possíveis soluções, inclusive daquelas com o menor sofrimento dos animais.

Não é escopo desse trabalho avaliar e discutir o antropomorfismo, um tema vasto e complexo. Porém a prevalência e dominância dessa postura/sentimento e consequente atitudes detectados nesse trabalho foram tão presentes, que junto com avaliações técnicas, sugestões de planos de manejo e, principalmente, nas discussões e comunicações com as pessoas a presença do antropomorfismo deve ser considerada como um fato presente e moldadora das atitudes. A origem dele é muito variada e amplamente difundida na sociedade, os exemplos comuns são os filmes do Walt Disney, reportagens sobre a vida de animais no canal Discovery, National Geographic e marketing para produtos "pet". Em verdade, o conjunto dessas informações embaralha na mente humana as categorias de animais, especialmente dos "pets" e animais selvagens. Há de se separar claramente para a sociedade o "pet", acompanhante, dependente dos humanos. Como esses animais estão presos às atitudes e vontades humanas, devem ter um tutor responsabilizável que não deve medir esforços e recursos para satisfação de suas necessidades. O animal selvagem por outro lado, é livre e mais independente do ser humano, e decorrente disso, exposto às regras da natureza pristina. Esses animais exigem, quando necessário, manejo ecológico, de preferência associado à preservação ou reconstituição de seus habitats ou ainda, o controle destinado a animais sinantrópicos quando proliferam em áreas antrópicas não pristinas. Implementar o tratamento destinado a pets para todos os animais é impossível técnica e financeiramente além de ser perigoso ao interromper processos naturais de equilíbrio com consequências potencialmente desastrosas.

\section{CONCLUSÃO}

Em conclusão, a capivara, carrapatos e febre maculosa são um problema que se adiciona a diversas outras de saúde pública que sobrecarregam as instituições públicas. Expôs-se neste trabalho, o intenso envolvimento emocional, que o problema alberga. Por outro lado, trata-se de um problema multifacetado, fundamentalmente ecológico e complexo que não admite soluções rápidas. Ater-se à realidade é um passo essencial para sua solução. Neste contexto, esconder ou minimizar perante a sociedade as características inerentes à vida selvagem em especial sua implacabilidade e mecanismos de equilíbrio gera uma situação perversa. Amenizar essa realidade é subtrair da sociedade elementos para tomada de decisões racionais efetivas assim como a noção dos ônus e bônus que acompanham cada escolha. A ausência dessa percepção mais real nas pessoas certamente suscitará descontentamento e desobediência civil independentemente de decisões tomadas.

\section{REFERÊNCIAS BIBLIOGRÁFICAS}

ALMEIDA, A. M. R. et al. Capivaras (Hydrochoerus hydrochaeris, Linnaeus, 1766) (Mammalia: Rodentia) em áreas verdes do município de Curitiba (PR). Estud Biol, v. 35, p. 9-16, 2013. https://doi.org/10.7213/estud.biol.7845

ALMEIDA, A. M. R.; BIONDI, D.; MONTEIRO FILHO, E. L. A. Dinâmica e biologia de uma população de capivaras em ambiente antrópico, Curitiba-PR. Cienc Nat, v. 35, p. 54-64, 2013. https://doi.org/10.5902/2179460X12560 
ANDRIOLA, A. ET AL. Severe population decline of marsh deer, Blastocerus dichotomus (Cetartiodactyla:Cervidae), a threatened species, caused by flooding related to a hydroelectric power plant. Zoologia, v. 30, p. 630-638, 2013. https://doi.org/10.1590/S1984-46702013005000015

ANGERAMI, R. N et al. A review of official reports and the scientific literature. Clin Microbiol Infect, v. 15 , p. 202-04, 2009.

BARDIN, L. Análise de Conteúdo. Lisboa: Edições 70; 2004.

BBC BRASIL. Após morte de menino por infecção, capivaras da Pampulha provocam debate ambiental e eleitoral em BH, 2016. Disponível em: < http://www.bbc.com/portuguese/brasil37458300>. Acesso em 09 de agosto de 2017.

BEM PARANÁ. Mascote oficial de Curitiba, capivara vira sucesso de vendas, 2015. Disponível em: <http://www.bemparana.com.br/noticia/395702/mascote-oficial-de-curitiba-capivara-vira-sucessode-vendas> Acesso em 09 de agosto de 2017.

BRASIL. INSTITUTO BRASILEIRO DE GEOGRAFIA E ESTATÍSTICA. Pesquisa nacional de saúde: 2013: acesso e utilização dos serviços de saúde, acidentes e violências: Brasil, grandes regiões e unidades da federação. IBGE, Coordenação de Trabalho e Rendimento. Rio de Janeiro: IBGE, 2015. $100 \mathrm{p}$.

BRATMAN, G. N.; HAMILTON, J. P.; DAILY, G. C. The impacts of nature experience on human cognitive function and mental health: Nature experience, cognitive function, and mental health. Ann $\mathbf{N}$ Y Acad Sci, v. 1249, p.118-136, 2012. https://doi.org/10.1111/j.1749-6632.2011.06400.x

BRICEÑO-LEON, R. Siete tesis sobre la educación sanitária para la participación comunitaria. Cad Saude Publica, v. 2, p. 7-30, 1996. https://doi.org/10.1590/S0102-311X1996000100002

CAMPOS-KRAUER, J.M.; WISELY, S. M. Deforestation and cattle ranching drive rapid range expansion of capybara in the Gran Chaco ecosystem. Glob Chang Biol, v. 17, p. 206-218, 2011. https://doi.org/10.1111/j.1365-2486.2010.02193.x

CUETO, G. R. Diseases of Capybara. In: MOREIRA, J. R.; FERRAZ, K.; HERRERA, E. A, MACDONALD, D. W., editors. Capybara Biology, Use and Conservation of an Exceptional Neotropical Species. New York: Springer-Verlag; 2013. p. 169-84.

DESBIEZ, A. L. J et al. Invasive species and bushmeat hunting contributing to wildlife conservation: the case of feral pigs in a Neotropical wetland. Oryx, v. 45, p. 78-83, 2011. https://doi.org/10.1017/S0030605310001304

FELIX, G. A. et al. Feeding behavior and crop damage caused by capybaras (Hydrochoerus hydrochaeris) in an agricultural landscape. Braz J Biol, v. 74, p. 779-86, 2014. https://doi.org/10.1590/1519-6984.02113

FERRAZ, K. et al Damage caused by capybaras in a corn field. Sci Agric, v. 60, p. 91-942, 2003. https://doi.org/10.1590/S0103-90162003000100029

GILLETT, J. D. The behaviour of Homo sapiens, the forgotten factor in the transmission of tropical disease.Trans R Soc Trop Med Hyg, v. 79, p. 12-20, 1985. https://doi.org/10.1016/0035$\underline{9203(85) 90222-6}$

GUIRAKHOO, F. et al. Safety and Efficacy of Chimeric Yellow Fever-Dengue Virus Tetravalent Vaccine Formulations in Nonhuman Primates. J Virol, v. 78, p. 4761-75, 2004. https://doi.org/10.1128/JVI.78.9.4761-4775.2004

KALIYAPERUMAL, K. Guideline for Conducting a Knowledge, Attitude and Practice (KAP) Study. AECS Illumination, v. 4, p. 7-9, 2004.

LABRUNA, M. B. Ecology of Rickettsia in South America. Ann N Y Acad Sci, v. 1166, p. 156-66, 2009. https://doi.org/10.1111/j.1749-6632.2009.04516.x 
LABRUNA, M. B. et al. Isolation of Rickettsia rickettsii from the tick Amblyomma sculptum from a Brazilian spotted fever-endemic area in the Pampulha Lake region, southeastern Brazil. Vet Parasitol Reg Stud Reports, v. 8, p. 82-5, 2017. https://doi.org/10.1016/j.vprsr.2017.02.007

LARSON, G.; FULLER, D. Q. The evolution of animal domestication. Annu Rev Ecol Evol Syst, v. 45, p. 115-36, 2014. https://doi.org/10.1146/annurev-ecolsys-110512-135813

MARCHINI, S.; CRAWSHAW, J. R. Human-Wildlife Conflicts in Brazil: A Fast-Growing Issue. Hum Dimens Wildl, v. 20, p. 323-28, 2015. https://doi.org/10.1080/10871209.2015.1004145

MC CARTHY, R. J.; LEVINE, S. H.; REED, J. M. Estimation of effectiveness of three methods of feral cat population control by use of a simulation model. J Am Vet Med Assoc, v. 243, p. 502-11, 2013. https://doi.org/10.2460/javma.243.4.502

MOREIRA, J. R. et al. Taxonomy, Natural History and Distribution of the Capybara. In: MOREIRA, J. R.; FERRAZ, K.; HERRERA, E. A.; MACDONALD, D. W.; editors. Capybara Biology, Use and Conservation of an Exceptional Neotropical Species. New York: Springer-Verlag; 2013. p. 3-37. https://doi.org/10.1007/978-1-4614-4000-0

MOREIRA, J. R.; PIOVEZAN, U. Conceitos de Manejo de fauna, manejo de população problema e o exemplo da capivara. Brasília: Embrapa Recursos Genéticos e Biotecnologia, 23 p. (Embrapa Recursos Genéticos e Biotecnologia. Documentos, 155, 2005. [citado 23 Out 2016] Disponível em: $<$ http://www.cenargen.embrapa.br/clp/publicacoes/doc/2005/doc155.pdf>. Acesso em: 30 set. 2019.

NAGASAWA, M. et al. Oxytocin-gaze positive loop and the co-evolution of human-dog bonds. Science, v. 348, p. 333-36. 2015. https://doi.org/10.1126/science.1261022

NASSER, J. T. et al. Urbanization of Brazilian spotted fever in a municipality of the southeastern region: epidemiology and spatial distribution. Rev Bras Epidemiol, v. 18, p. 299-312, 2015. https://doi.org/10.1590/1980-5497201500020002

PINHEIRO, M. S.; MOREIRA, J. R. Products and uses of Capybara. In: MOREIRA, J. R.; FERRAZ, K.; HERRERA, E. A.; MACDONALD, D. W., editors. Capybara Biology, Use and Conservation of an Exceptional Neotropical Species. New York: Springer-Verlag; $2013 . \quad$ p. 211-227. https://doi.org/10.1007/978-1-4614-4000-0 12

QUEIROGAS, V. L. et al. Capybaras and ticks in the urban areas of Uberlândia, Minas Gerais, Brazil: ecological aspects for the epidemiology of tick-borne diseases. Exp Appl Acarol, v. 57, p. 75-82, 2012. https://doi.org/10.1007/s10493-012-9533-1

RODRIGUES, M. Hidrelétricas, Ecologia comportamental, resgate de fauna: uma falácia. Nat Conserv, v. 4, p. 29-38, 2006.

SÃO PAULO. Secretaria de Estado do Meio Ambiente e a Secretario de Estado da Saúde de São Paulo. Resolução Conjunta SMA/SES No 01, de $1^{\circ}$ de julho de 2016. Dispõe sobre a aprovação das "Diretrizes técnicas para a vigilância e controle da Febre Maculosa Brasileira no Estado de São Paulo - classificação de áreas e medidas preconizadas", e dá outras providências. Diário Oficial, São Paulo, SP, 02 jul. 2016. Seção 1, p. 41-92.

SMEETS, R. E. H. et al. Severe coagulopathy after a bite from a 'harmless' snake (Rhabdophis subminiatus). J Intern Med, v. 230, p. 351-354, 1991. https://doi.org/10.1111/1.13652796.1991.tb00455.x

SOUZA, C. E. et al. Experimental infection of capybaras Hydrochoerus hydrochaeris by Rickettsia rickettsii and evaluation of the transmission of the infection to ticks Amblyomma cajennense. Vet Parasitol, v. 161, p. 116-121, 2009. https://doi.org/10.1016/j.vetpar.2008.12.010

SZABÓ, M. P. J.; PINTER, A.; LABRUNA, M. B. Ecology, biology and distribution of spotted-fever tick vectors in Brazil. Front Cell Infect Microbiol, v. 3, p.27, 2013. https://doi.org/10.3389/fcimb.2013.00027 
UNIVERSIDADE FEDERAL DE UBERLÂNDIA - UFU. A cidade de Uberlândia. [citado em 02 dez 2016]. Disponível em: <http://www.ufu.br/catalogo_novo/idiomas/pt/cidade.htm.> Acesso em: 30 set. $\underline{2019}$.

VANDAMME, E. Concepts and challenges in the use of Knowledge-Attitude-Practice surveys: Literature review. Department of Animal Health Institute, Institute of Tropical medicine, Antwerp; 2009. [citado em 15 mai 2015] Disponível em: <http://www.snndz.net/resources/literature-reviews/fullreviews/.>. Acesso em: 30 set. 2019.

VERDADE, L. M.; FERRAZ, K. Capybaras in an anthropogenic habitat in southeastern Brazil. Braz J Biol, v. 66, p. 371-78, 2006. https://doi.org/10.1590/S1519-69842006000200019 